\title{
Roundabouts for safer roads
}

\author{
E. De Winne \\ Faculty of Engineering Sciences, Department Civil Techniques, \\ Ghent University, Belgium \\ Flemish Ministry of Mobility and Public Works, Belgium
}

\begin{abstract}
This paper describes guidelines and research results about the design of roundabouts and their effects on traffic safety.

After an introduction, the principal geometric elements of a roundabout are discussed in relation to traffic safety. Attention is given to specific accommodation for cyclists and pedestrians.

Next, international research results concerning roundabouts and effects on traffic safety are discussed. Some methodological aspects as well as conclusions from research are dealt with. It is explained why roundabouts have positive effects on traffic safety.

Finally, the research results are described, as well as the global effects of roundabouts on traffic safety and specific results for bicyclists and pedestrians. Some case studies, and particular roundabout designs, such as the "turboroundabout" or the oval-roundabout, are treated and the relationship between design elements and traffic safety was explored, together with conclusions and suggestions.
\end{abstract}

Keywords: roundabouts, traffic safety, turbo-roundabout, oval-roundabout.

\section{Introduction}

The primary characteristics of modern roundabouts reduce many of the safety hazards of traditional intersections and nonconforming traffic circles.

The physical configuration of a modern roundabout, with a deflected entry and yield-at-entry, forces a driver to reduce speed during the approach, entry, and movement within the roundabout.

This is contrary to an intersection where many drivers are encouraged by a green of yellow light to accelerate to get across the intersection quickly and to 
"beat the red light" and contrary to old traffic circles where tangent approaches also encourage, or at least allow, high-speed entries.

Another important safety factor is that the only movement at an entry and an exit of a roundabout is a right turn, thus reducing the potential frequency and severity of accidents compared to accidents typically occurring during left turns and when traffic crosses an intersection in perpendicular directions.

\section{Geometric design of a roundabout $[1,6,9]$}

The interaction between speed, design vehicle, not motorized road user and alignment determine whether a roundabout is satisfying on the alleged safety and capacity goals.

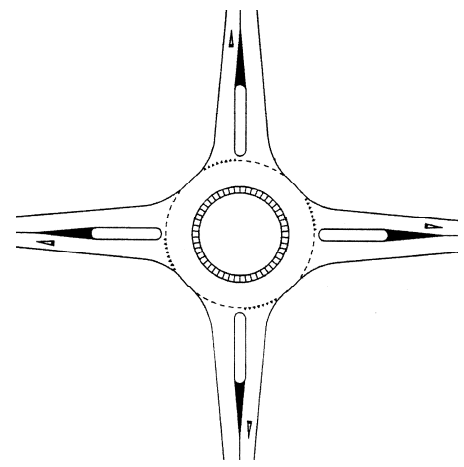

Figure 1: $\quad$ Construction of a roundabout (CROW 1998 [3]).

\subsection{Middle island}

There are no minimum or maximum sizes for the middle island declared. A mini roundabout has a middle island with a diameter less than $4 \mathrm{~m}$.

\subsection{Hotheaded available strip}

The outer part is hotheaded rendered with a light level of $3 \mathrm{~cm}$, in coloured or profiled pavement materials, for the driving of lorries and busses. Recommended width: Flanders: $1,5 \mathrm{~m}$; Wallonia: 2 to $4 \mathrm{~m}$. USA: 1 to $4 \mathrm{~m}$ and a slope of 3 to $4 \%$ (decreasing from the centre to the edge).

\subsection{Inside radius - diameter}

A smaller radius leads to higher speed because the lateral displacement is smaller. Diameter: $3 \mathrm{~m}$ (mini roundabout) - $35 \mathrm{~m}$ (single lane roundabout) - and until $60 \mathrm{~m}$ or more (more lane roundabout).

\subsection{Outside radius - diameter}

A fixed drive line without wheel correction requires outside diameters of $13 \mathrm{~m}$ (mini roundabout) until $80 \mathrm{~m}$ (big more lane roundabout) 
Types:

- $\quad$ mini roundabout: from $18 \mathrm{~m}$ to $25 \mathrm{~m}$

- compact roundabout: between $25 \mathrm{~m}$ to $40 \mathrm{~m}$

- $\quad$ large roundabout: between $35 \mathrm{~m}$ and $50 \mathrm{~m}$ and more

In the USA roundabouts are divided into functional categories:

- mini roundabout: from $13 \mathrm{~m}$ to $25 \mathrm{~m}$

- urban compact roundabout: outside diameter: $25 \mathrm{~m}$ to $30 \mathrm{~m}$

- urban single lane roundabout: outside diameter: $25 \mathrm{~m}$ to $30 \mathrm{~m}$

- urban double lane roundabout: outside diameter: $30 \mathrm{~m}$ to $40 \mathrm{~m}$.

- not urban single lane roundabout: outside diameter: $35 \mathrm{~m}$ to $40 \mathrm{~m}$

- not urban double lane roundabout: outside diameter: $55 \mathrm{~m}$ to $60 \mathrm{~m}$

In Great Britain, Wallonia and France: no specific functional categories except for a mini roundabout.

Nowhere, maximum values for the dimensions of roundabouts are used

\subsection{Track and lanes}

In France and the USA: lane width on a single lane roundabout is $120 \%$ of the lane width on the entry.

In France: minimum width $7 \mathrm{~m} ; 6 \mathrm{~m}$ is possible providing a portable strip.

In Flanders: $6 \mathrm{~m}$ for mini roundabouts; $5 \mathrm{~m}$ for big single lane roundabouts; 8 $\mathrm{m}$ to $9 \mathrm{~m}$ for double lane roundabouts.

From a roadway width of $8 \mathrm{~m}$, the roundabout is functioning as a double roundabout, even if there are no markings between the lanes.

The slope of the track is between 2 and $2.5 \%$, descent to the outside.

\subsection{Markings on lanes}

On a single lane roundabout, a concentric marking can be applied. On more lanes roundabout, road markings are applied to the lanes to separate visual the different lanes.

In France and the USA: the opinion is that concentric markings give a false sense of security.

In Great Britain: the opinion is that concentric markings increase the capacity and safety.

\subsection{Connecting arcs: entry/exit}

In Flanders and the Netherlands: radial connecting of entries and exits are safer for cyclists and pedestrians.

In Anglo-Saxon countries and on large roundabouts in France: tangential lines of the driveways with smooth transition. On tangential connections, the speed of the approach movement is similar to the speed of the leaving movement (maximum velocity difference $<20 \mathrm{~km} / \mathrm{h}$ ). On tangential connections the speed of the motorized traffic is homogeneous, which conflicts between faster and slower traffic should be avoided and the capacity increases. 
In Great Britain: driveways to large number of cyclists without feather more runs connected.

Arc curves for connecting entries: Flanders: 8 to $12 \mathrm{~m}$ (smallest) - Wallonia: 10 to $20 \mathrm{~m}$ - USA: 10 and $30 \mathrm{~m}$ - Great Britain: $30 \mathrm{~m}$ maximum. The radius of the exit may never be less than the radius of entry.

\subsection{Entries and exits}

The presence of broad middle conductors offers advantages for safety, capacity and road management, e.g.

- for cyclists and pedestrians they allow a crossing in two stages

- they are more alert on the road approaching a roundabout

- they affect the arriving road traffic a better estimate possible if the oncoming road traffic continue driving on the roundabout or is leaving the roundabout (higher capacity).

- $\quad$ an ideal implantation site for signs may be possible.

In Flanders: centre conductors are recommended for roundabouts with a middle island of $15 \mathrm{~m}$ or more.

In the Netherlands: from $16 \mathrm{~m}$ diameter

In France: centre conductors are recommended minimum of $0.8 \mathrm{~m}$ and preferably $2 \mathrm{~m}$ at roundabouts in urban environment.

In Great Britain: the designer is free to decide whether or not to use centre conductors

In terms of security, entries on one lane are preferable (even in a $2 \times 2$ road). Only for compact reasons, there are entries and exits to two lanes are preceded.

Driveways with one lane: Flanders: a preferred width of $3,2 \mathrm{~m}$ to $4 \mathrm{~m}-$ Wallonia: $4 \mathrm{~m}$ - the Netherlands: $3,5 \mathrm{~m}$ to $4 \mathrm{~m}$ - France: $3 \mathrm{~m}$ to $4 \mathrm{~m}$ - USA: 4,3 $\mathrm{m}$ to $4,9 \mathrm{~m}$.

\subsection{Bypass}

In some cases it may be possible to construct a roundabout with one or more branches with an extra lane for a right movement (bypass), which allows moving beyond the roundabout, in order to solve capacity problems in specific branches.

By the expected high speeds in bypasses, in the Netherlands it is not recommended to cross cyclists on the same ground level. Another possibility is at the bicycle crossing on the bypass, an increased device can be constructed to which the speed of motorized traffic is slowed.

\subsection{Bicycle facilities $[4,5]$}

There are four ways to lead cyclists on roundabouts: fully uneven ground, through a dedicated bike path, through an adjacent bicycle path and on the same road of motorized traffic (mixed traffic) 


\section{Mixed settlement}

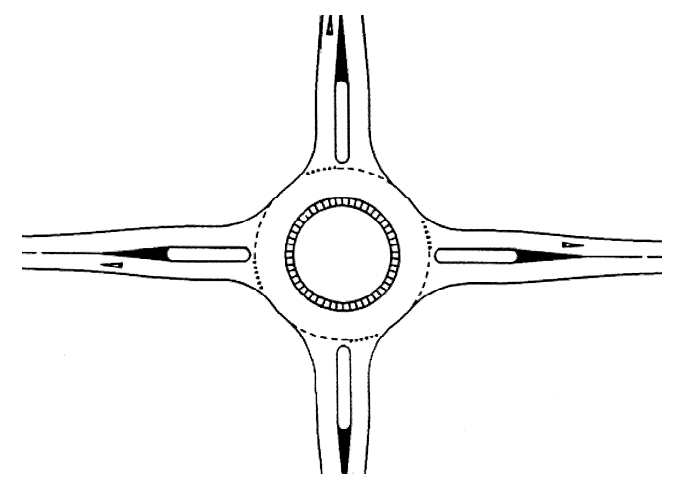

Figure 2: $\quad$ Roundabout with mixed settlement for cyclists (CROW 1998 [3]).

\section{Roundabout with bike lane}

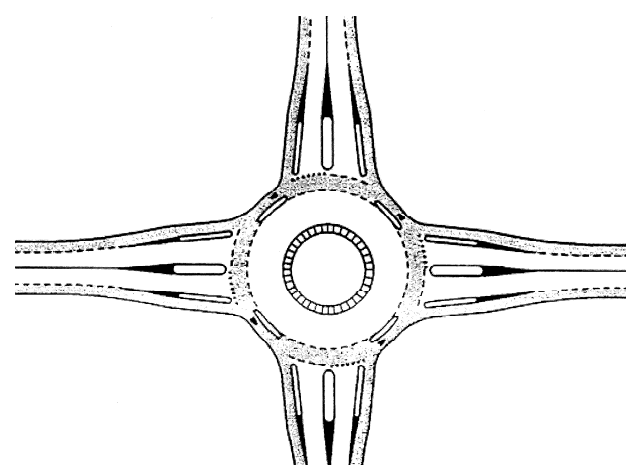

Figure 3: $\quad$ Roundabout with bike lane (CROW 1998) [3].

\section{Free bike path}

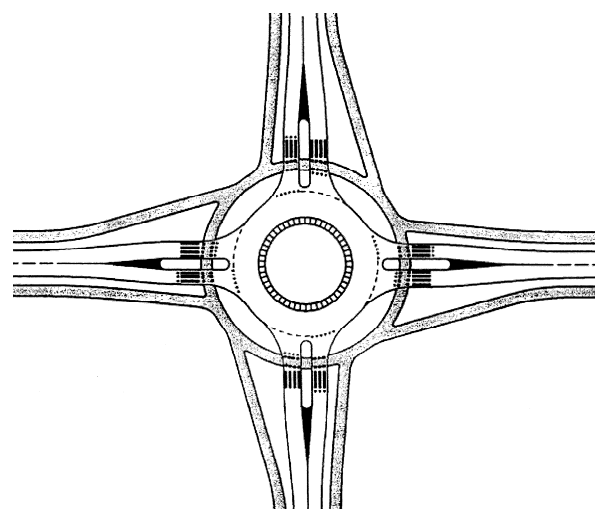

Figure 4: $\quad$ Roundabout with free bike path in the priority (CROW 1998 [3]). 


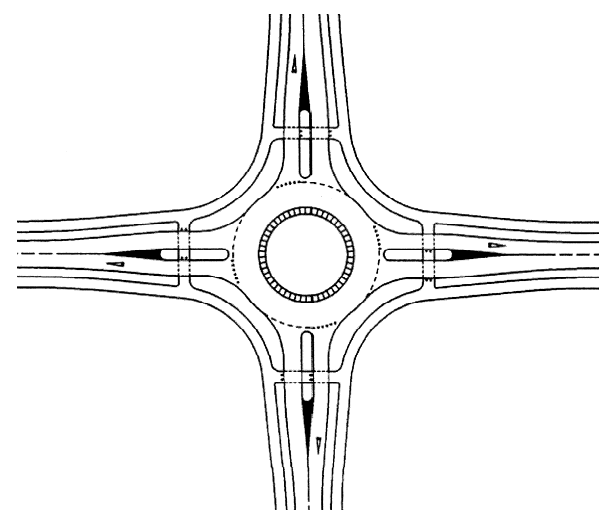

Figure 5: $\quad$ Roundabout with free bike path out of the priority (CROW 1998 [3]).

\subsection{Complete separated settlement}

In the line is the traffic for the cyclists on the floor in the roundabout. At large roundabouts with double entrances and exits, traffic areas, the uneven ground crossing of bike paths with the roundabout, which is reserved to the car, is recommended.

In Flanders: the type of bicycle facility (mixed, adjacent, free lying) depends on the spatial organization (transport sector, transition, like area) and the dimension (large, compact and mini). In compact and large roundabouts in transitional areas, the cyclist can hold in the priority on a free-lying bike path.

In Wallonia: specific measures if they are fit into a cycle track network in a wider environment. In major cycling intensities (from 800 cyclists per hour) and if no space, is a separate designated bike path recommended

In Great Britain: roundabouts are dangerous for cyclists, which are not run on roundabouts. Possible alternatives are the establishment of separate bicycle and foot paths at some distance from the roundabout, pointing out on alternative route, or complete roadway separating vulnerable road users e.g. cycling through tunnels.

In USA: is recommended to present a possible cycle track on an entry of a roundabout at $30 \mathrm{~m}$ for the roundabout to turn in the road, which cyclists and motor vehicles are using just before the roundabout and on the same infrastructure.

In France: on urban roundabouts the nature of the cycle track depends on the dimension of the roundabout.

- on mini roundabouts: no bicycle facilities needed;

- $\quad$ on roundabouts with an outside radius of between $12 \mathrm{~m}$ and $22 \mathrm{~m}$ : the cycle track to stop at around $15 \mathrm{~m}$ for the roundabout and then, the rider from mixing with motorized traffic;

- $\quad$ on roundabouts with an outer radius of more than $22 \mathrm{~m}$ : an adjacent market bicycle path. 


\subsection{Pedestrian crossings}

The pedestrian crossing is at a sufficient distance from the roundabout itself to be made

In USA: minimum 7,5 $\mathrm{m}$ (one vehicle length); in Wallonia: $4 \mathrm{~m}$ recommended. In the Anglo - Saxon countries, however it depends on the design of the tangential connection on the entry on the roundabout. However, an oasis in the centre conductor is provided which must be wide enough (about 1,8 m) and can also be used as a crossing for wheelchair users and prams. Crossing facilities for pedestrians shall be carried out with zebra - paths.

\subsection{Facilities for heavy and exceptional transport}

The inner radius and the available road width must be sufficient large. In some cases, by stabbing in the middle island or on a bypass be constructed, which can be completed with lockable gates or barriers. Another possibility is addressed further in portable strips to put on the outside of the roundabout.

As some truck categories are constructed with a ground clearance of only 0,12 $\mathrm{m}$ in empty, it is recommended that the height difference between the portable strip and the road is up to $0,08 \mathrm{~m}$ to carry out.

It is recommended that in case of high freight rates and bus routes, a bicycle and pedestrian traffic is settled on uneven ground.

\subsection{Public transport [9]}

Bus and tram lines can be made parallel to and right of the driveway. Such a bus (tram) strip can either continue to the roundabout or just before the roundabout to reach the driveway. Alternatively, a bus (tram) job in the middle of the road to which public transport via a reserved strip, lights in the roundabout can work, if equipped with additional traffic to the impending public transport to give forwards hinder the movement.

\subsection{Lighting [9]}

It is necessary to light up the middle island or ensure that elements that light up in the glow of the headlights for the vehicle are present. The roundabout is the best on the outside to the middle island illuminated well to radiation. On the middle island is best use made of clear materials that reflect light better. The edge of the middle island should be clearly marked.

\subsection{Special forms [9]}

\subsubsection{Turbo roundabout}

A turbo roundabout (traffic circle or spiral) is a double lane roundabout where the road has a special effect. At the roundabout, the lanes are physically separated. The middle island is not circular but two sides a little out skirts so in fact an egg-shaped roundabout arises. So the movement is channelled and the number of weaving motions is reduced, which is less conflict and a better flow in 
the hand to work. The advantages of this are that traffic in one dominant direction has priority due to the construction, and the capacity of the roundabout increases.

\subsubsection{Double roundabout}

A double roundabout (traffic circle or glasses) is a concept where two roundabouts via a short connection to each other are linked.

In Great Britain the term is used for a roundabout consisting of two centre islands as one whole operation.

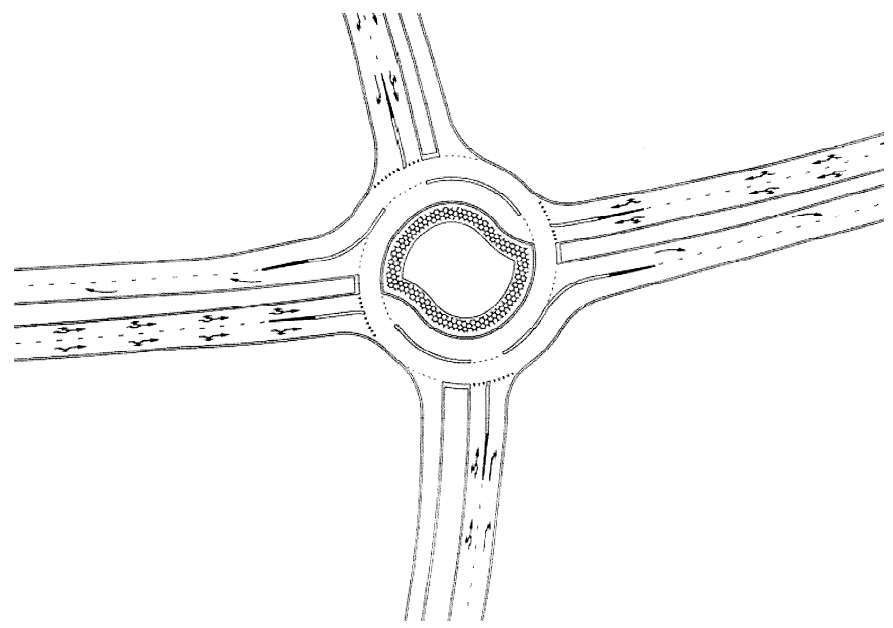

Figure 6: Turbo roundabout (CROW 2002 [5]).

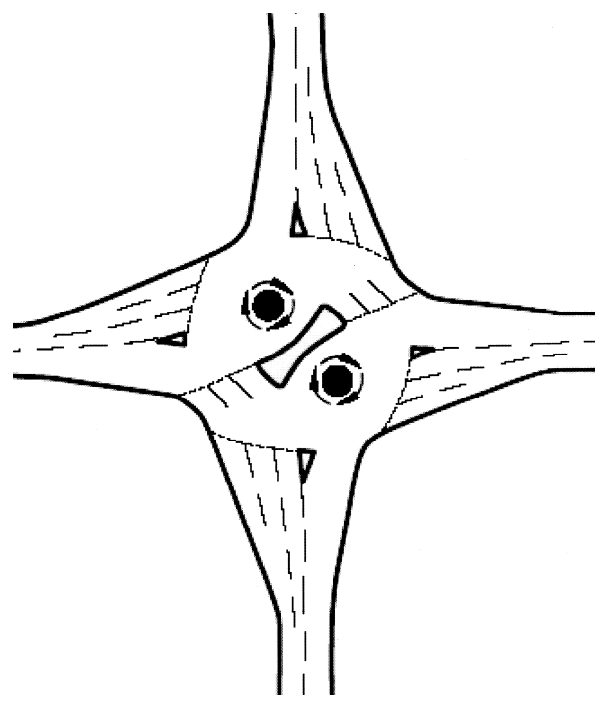

Figure 7: British double roundabout (GBA [10]). 


\subsubsection{Bone roundabout}

A bone roundabout can be defined as a double roundabout where a part needed for the return movements between the two roundabouts is not recognized; so a double roundabout is created similar to a bone (or a roundabout that is called bottonde or barbell).

\subsubsection{Oval roundabout}

The elliptic or oval roundabout (or ovonde) is a roundabout with an oval middle island. An ovonde can be made between two (imaginary) half roundabouts where a straight line creates at least $25 \mathrm{~m}$.

\subsubsection{Mini roundabout}

Mini roundabouts are built in places with limited place. In Flanders there exists an interest in mini roundabouts. The law allows the term "roundabout" only if the middle island is constructed and all the directions (included for heavy trucks) around the middle island drive.

\section{Effects of the construction of a roundabout on traffic safety [6-9]}

- Most investigations into the safety effects of roundabouts are studies which are correcting the effects of trends and regression to the mean. Quite a few studies do not take into account at least one of these effects.

- Roundabouts improve traffic safety. After construction of the roundabout, the number of accidents involving at least one slightly injured fell by an average of $34 \%$. Accidents with at least one seriously injured fell by an average of $38 \%$. The results are statistically significant.

- It appears that the impact of roundabouts on heavier casualties is greater than on lighter end accidents or accidents involving only material damage. For the last category is the impact uncertain.

- Transformation of an intersection to a roundabout ensures that speed in the area $(300 \mathrm{~m})$ of the intersection is significantly reduced. There is also a link between the speed and the lateral movement in the roundabout which should be made. The latter is determined by the diameter of the middle island and the connecting angle of the entry at the roundabout.

- The decrease in the number of accidents is likely but not certain greater on priority controlled intersections than on regular light intersections

- Probably, the construction of roundabouts results in a decrease in the number of injury accidents for cyclists. Certainly, the conclusion is not. The observed decrease in the number injury accidents is lower for cyclists than for other road users.

- There is no conclusive evidence about the difference in un-security as to the type bike for free bicycle paths, adjacent bicycle paths, no bike facility. The results allow conclude that roundabouts with dedicated bike paths are safer than roundabouts for cyclists with bicycle lanes or adjacent bicycle lanes or roundabouts with mixed traffic. 
- Dedicated bicycle lanes with cyclists in the priority have in the average a slightly higher frequency of bicycle accidents than dedicated bike paths with cyclists out of the priority.

- The frequency of accidents involving pedestrians at roundabouts is lower than regular light junctions.

- There is a directly proportional relationship between speed and accidents on roundabouts and a positive relationship between traffic volume and accidents

- A smaller middle island is probably better for the road safety than a large middle island. For cyclists however, a larger middle island is probably more safe

These results largely confirm the theoretical assumptions about the positive effects on road safety.

- The number of accidents with injured decreases significantly after the construction of a roundabout. The number of accidents involving heavy end decreases more than the number of accidents involving lighter end.

- The speed of traffic approaching and leaving the roundabout is significantly lower than in the period before the construction of the roundabout. The effect is measured at $300 \mathrm{~m}$ from the roundabout.

It can be said that the reason why the traffic unsafety at roundabouts decreases possibly is should be sought in the reduced speed in the activities of the conflicts affecting, the probabilities of an accident with major injuries gravity is lower, rather than reducing the number of shifting the nature of the conflict.

\section{Recommendations and conclusions [9]}

- Test elements remain: the influence of specific geometric features (dimensions, connections, number of lanes, lighting, etc...) of roundabouts on road safety, the effects of roundabouts for different types of users (e.g. cyclists, pedestrians, motorcyclists, ...) and the effects on some special types of roundabouts as turbo roundabouts, mini roundabouts, ovondes, etc.... Specifically for Flanders, research into the effects of different types of bicycle facilities is of any interest. Further research into the difference in the safety impact of a roundabout to the situation (environment characteristics, intersection design, traffic intensity, and composition) at the intersection is useful.

- The guidelines often offer a relatively large freedom of choice to the designers. It would be useful to make an inventory of current practice in the construction of roundabouts in Flanders. This can be best done by a field observation to carry out a number of characteristics of existing roundabouts (size roundabout, median island size, number of lanes, bicycles facilities, and pedestrian facilities). The data obtained from such an inventory can be used for any further research and management purposes by the road authorities. In addition, they offer interesting information on the frequency of certain types of roundabouts (more lane roundabouts, dual entries, dedicated bicycle paths, double roundabouts, compact roundabouts, roundabouts in urban areas, etc...) in practice. 
- The mentioned survey may reveal the extent to which some guidelines whether or not in practice has been carried out for any reason. A better understanding of the reality is likely to lead to adjustments or refinements. Furthermore, the experience with roundabouts in Flanders significantly increased and additional research and experiences abroad are available.

- Roundabouts do have a positive impact on traffic safety. In Flanders Belgium an average decrease of $34 \%$ of the number of injury accidents was noticed after construction of a roundabout. Also for pedestrians and bicyclists, roundabouts seem to generate positive safety effects. Nevertheless this effect seems to be insured and is probably smaller than for other road users.

- Important is to know that everywhere the same rules for roundabouts are applied: the traffic on the roundabout has priority over the traffic that the roundabout would approach.

- Roundabouts are designed in different sizes to serve various objectives and conditions. Even mini-roundabouts (with a diameter of $25 \mathrm{~m}$ or less) are effective at reducing speed and improving safety. Small to medium roundabouts are 25 to $40 \mathrm{~m}$ in diameter. The larger roundabouts (with a diameter greater than $40 \mathrm{~m}$ ) provide greater separation of traffic and a higher capacity.

\section{References}

[1] Debaere, K., Vandeputte, J., Aanbevelingen voor de aanleg van rotondes, Vademecum Rotondes, Ministerie van de Vlaamse Gemeenschap, Brussels, 1997.

[2] Donné, V., Verlichting van rotondes, 1997.

[3] CROW, Eenheid van rotondes, CROW-publicatie 126, Ede, Nederland, 1998

[4] MVG, Vademecum Fietsvoorzieningen, Brussel, Ministerie van de Vlaamse Gemeenschap, 2001.

[5] CROW, Fietsoversteken op rotondes: supplement bij publicatie 126 'Eenheid in rotondes': CROW-publicatie 126a, Ede, Nederland, 2002.

[6] MET, Evaluation et accidentologie des giratoires et feux tricolores, Namur, Ministère Wallon de l'Equipement et des Transports, 2003.

[7] Nuyts, E., Cuyvers, R., Effectiviteitsmeting bij voor-na studies met een vergelijkingsgroep: rapport 2003-22, Diepenbeek, Steunpunt Verkeersveiligheid, 2003.

[8] De Brabander, B., Nuyts, E., Vereeck, L., Road safety effects of roundabouts in Flanders, Rapport RA-2005-63, Diepenbeek, Steunpunt Verkeersveiligheid, 2005.

[9] Daniels, S., Wets, G., Invloed van rotondes op verkeersveiligheid, Steunpunt Vlaanderen, Universiteit Diepenbeek, 2006.

[10] GBHA (1993), Design manual for roads and bridges, geometric design of roundabouts; TD16/93, London Great Britain, Highway Agency. 